\title{
THE REHABILITATION OF PARAPLEGICS AND TETRAPLEGICS IN WEST GERMANY
}

\author{
F. W. MEINECKE, M.D. \\ The Spinal Injuries Centre, Department of Surgery, \\ Workmen's Compensations Hospital 'Bergmannsheil', Bochum, Germany
}

To understand the organisation of medical services in West Germany, its system of insurances must be appreciated. The majority of German citizens are insured with 'Krankenkassen' (sickness-insurance authorities), who pay the cost of treatment in accident cases only, if no other organisation is responsible. Accidents at work, or on the way to and from work, are covered by compulsory accident insurance. Details of the variety of insurance contributors will not be described here, as they have, in part, been the subject of an earlier contribution (Meinecke, I964).

In the absence of a National Health Service on the British pattern the costs arising from the patient's sickness or disability have to be borne by a number of different agencies. In accident cases the distribution of financial resources depends on the individual provisions for insurance of the patient at the time of onset of his disability. In cases of illness a combination of insurance resources is required to ensure rehabilitation from start to finish.

The German doctor requires to be an expert in the complexities of mutually exclusive or complementary subvention at every stage of rehabilitation, and must approach the correct authority for each aspect. Under the present system each member of a team of insurances is responsible for the cost of its own domain of the rehabilitation process. Paraplegia, with its many facets of medical, social and occupational rehabilitation, is a good example.

Compulsory Accident Insurance (Employers' Liability Insurance Assoications.). Since their early days trade-unions have accepted their duty to provide the best possible treatment and equipment for their members, and to ensure whenever possible their return to work without undue delay. This includes the adaptation of the home and retraining for a return to full-time work. They have their own hospitals and special departments and special personnel to sort out domestic and work-problems whilst patients are under treatment. Compensation problems are dealt with in good time but will not be discussed further here.

Special departments exist for the treatment of burns, and for paraplegia. For paraplegia such workmen's compensation hospital departments have been expanding over the years. All industrial enterprises and hospitals under contract with the trade-unions are advised to transfer cases of paraplegia or tetraplegia either at once or as soon as possible to these special centres. Notification by telephone or telegram has to be given and the administration is responsible for providing a bed at once, even if beds are hard to find.

Geographically these centres are well distributed and the number are sufficient for the needs of the patients with work-connected injuries both for the first admission, and subsequently if re-admission for the treatment of complication is necessary.

Regular visiting at home and at work after discharge ensures effective aftercare. Registration provides exact data regarding numbers, which are at present 
between I30 and I5O per annum. In addition, paraplegic patients who are not insured by the workmens' compensation are admitted when possible. When retraining is needed, special training centres are approached through the labour authorities.

Other Insurance Organisations. Patients outwith trade-union insurance, or members of the services, are looked after by sickness insurance. They include those injured on the roads, at sport or at home and cases of paraplegia due to medical and congenital causes. The total number considerably exceeds that of work accidents. Since they are not subject to registration, their incidence is still a matter of guesswork but probably amounts to between 400 and 850 cases per annum.

Of these patients only a few can be taken care of by the small number of special centres outside the workmens' compensations hospitals. The majority are still treated in general hospitals where there is neither special knowledge nor staff or equipment available, with the result that complications are frequent and unfavourable results are common. The provision of special aids, domestic adjustments and facilities for return to work is financed by sickness insurance, social agencies or other insurers. Re-training or apprenticeships are provided either by the firms themselves or in special institutions. The doctor acts as a liaison officer for the coordination or rehabilitation.

Occupational Rehabilitation. Disabled children are admitted to special boarding schools, unless suitable facilities exist near their homes. There is still a shortage of places at secondary school level and only one special college at one University exists for disabled students. The boarding schools provide technical and commercial courses and there are two special schools for paraplegics and three which admit wheelchair patients. The number of places meet present needs. Patients are referred via the labour administration, legal accident insurance, social agencies and insurance companies. Whilst training proceeds, a workplace near their future home is found for them.

The Armed Forces. If an accident occurs while a member of the armed forces is on duty, the forces are responsible for defraying the cost of both treatment and rehabilitation. If not, their responsibility is limited to a certain period, after which sickness insurance and social aid agencies require to take over. Army hospitals do not have special centres, but, if possible, send service personnel to workmens' compensations hospitals. They also arrange for return to work, but will pay the cost only if the accident occurred while on duty.

\section{SUMMARY}

Facilities are sufficient and rehabilitation is uninterrupted in West Germany for patients with paraplegia following accidents at work. For all other paraplegic patients co-ordination and facilities leave something to be desired, as has frequently been pointed out in the literature.

During the past few years there has been a gradual improvement with closer cooperation and integration of essential services. Registration of all new lesions would be a great asset.

It has to be realised that, as the quality of initial treatment improves, the 
number of those able to benefit from rehabilitation will increase. Provision for this requires to be made and a number of problems remain to be solved.

When Guttmann, Io years ago first returned to Germany, only a few departments were able to provide adequate treatment. By demonstrating his results he has convinced his colleagues and the administrators; and by his active encouragement he has drawn attention to the many problems still awaiting solution.

Visits to, and periods of work at Stoke Mandeville have shown what can be achieved by doctors, administrators, nurses and physiotherapists. Particularly impressive has been the organisation of sport for the disabled, which, in the words of one of our team at the Games in Tokio in I964, has made the paraplegic socially 'respectable'.

The last Io years in particular have brought much progress in the rehabilitation of the paraplegic. The workmens' compensation hospitals have played a leading part, but beyond this these new ideas have now been accepted by all concerned, including patients themselves. This is proved by the opening of new centres, by the increase in the numbers of paraplegics at work and in sport, and by numerous professional meetings devoted to the subject. Organisations for the disabled have also played their part.

All this would not have happened without Ludwig Guttmann. In Germany, too, he is the 'father' of the paraplegic and his name is known to all. May his drive remain the stimulus for improving the fate of the paraplegic in the future as it has been in the past.

\section{REFERENCE}

MeineCke, F. W. (1964). Int. F. Paraplegia, 2, I63. 